\title{
Resor Ekologis di Titik Nol Indonesia
}

\author{
Ahmad Shiddiq Hambali dan Ima Defiana \\ Departemen Arsitektur, Fakultas Teknik Sipil dan Perencanaan, Institut Teknologi Sepuluh Nopember (ITS) \\ e-mail:may_d@arch.its.ac.id
}

\begin{abstract}
Abstrak - Industri pariwisata merupakan kesempatan besar dalam pertukaran ekonomi dan budaya masyarakat. Indutri yang tidak mengandalkan sumber daya yang semakin berkurang, akan tetapi sebaliknya, untuk memajukan sektor pariwisata kita harus memelihara alam yang merupakan nilai jual utamanya. Indonesia dengan segala kekayaan alamnya memiliki potensi yang sangat besar untuk unggul dalam dunia pariwisata. Salah satu tempat yang memiliki potensi tersebut berada di ujung Sumatera, tepatnya di Pulau Sabang. Pulau yang ditasbihkan sebagai Destinasi Pariwisata Nasional tersebut memiliki banyak sekali potensi alam untuk diekspos. Namun, kurangnya fasilitas penunjang wisata menjadi suatu kendala yang harus diselesaikan. Padahal dengan dicanangkannya festival Yacht bertaraf Internasional disana, haruslah dibarengi dengan pembangunan sarana penunjang. Membangun resor dinilai menjadi pilihan yang sangat tepat karena selain digunakan sebagai tempat menginap, resor juga dapat dimanfaatkan lebih luas sebagai ikon sekaligus sarana pengenalan wisata dan budaya setempat. Resor yang didesain dengan pendekatan ekologis agar tidak merusak lingkungan serta memaksimalkan potensi alam yang ada di Pulau Sabang.
\end{abstract}

Kata Kunci-Pariwisata, Pulau Sabang, Festival Yacht, Resor, Ekologis.

\section{PENDAHULUAN}

$\mathrm{P}$ ARIWISATA merupakan sektor yang sangat setrategis dalam meningkatkan pendapatan masyarakat dan Negara. Namun, Kehadiran pariwisata yang bersifat industri cenderung hanya mengutamakan nilai ekonomi tanpa pertimbangan kondisi alam, sosial, dan budaya. Sehingga industri wisata menjadi kesempatan, tapi sekaligus ancaman.

Oleh karena itu, dibutuhkan pendekatan ekologis dalam pengembangan bidang kepariwisataan. Berbeda dengan industri migas yang berdasar pada bahan bakar fosil, pariwisata tidak tergantung pada sumber daya yang makin berkurang. Justru, agar pariwisata semakin berkembang, harus dilakukan upaya untuk meningkatkan kualitas lingkungan dan memelihara keseimbangan ekologis [1].

Wisata ekologis yaitu kegiatan pariwisata dikembangkan sebagai sebuah perjalanan bertanggung jawab ke wilayahwilayah alam, yang melindungi lingkungan dan meningkatkan kesejahteraan masyarakat setempat [2].

Pulau Sabang (Gambar 1) selaku pulau paling ujung di Indonesia, atau biasa disebut titik nol, merupakan salah satu ikon pariwisata Indonesia. Pantai Gapang (Gambar 2 \& 3) yang berada di Pulau Sabang dijadikan sebagai lokasi objek desain karena potensi Pantai ini yang akan dijadikan sebagai tempat dilaksanakannya event International Marine Festival. Selain itu, di pantai ini jugalah yang nantinya akan dibangun pelabuhan khusus pariwisata, menjadikan pantai ini sebagai pantai yang perkembangan pembangunannya harus sangat diperhatikan.

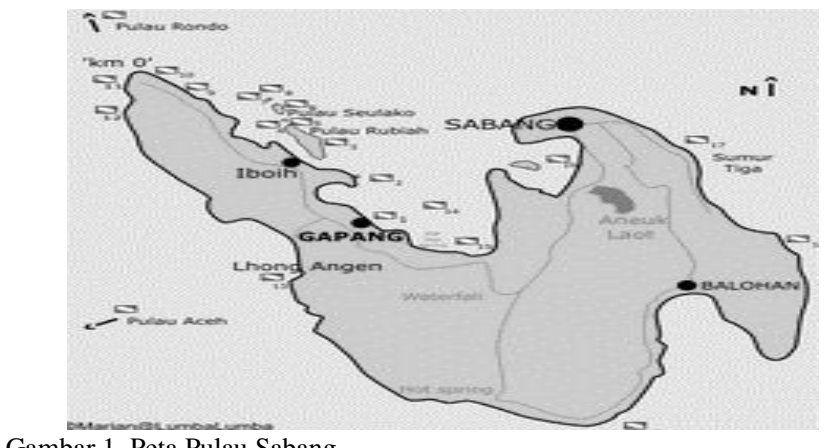

Gambar 1. Peta Pulau Sabang

Sumber: Travellers.web.id

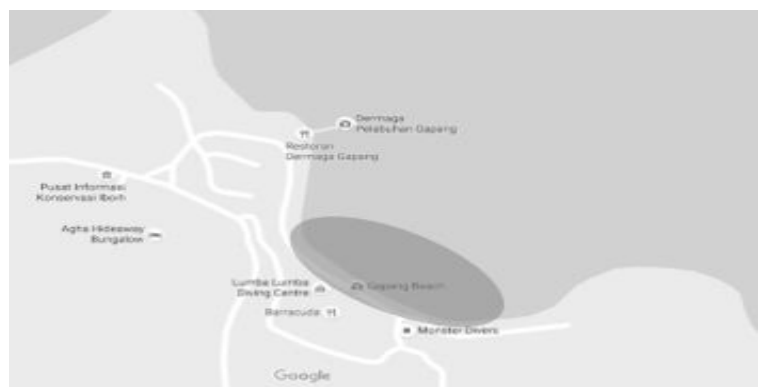

Gambar 2. Lokasi Pantai Gapang

Sumber: Travellers.web.id
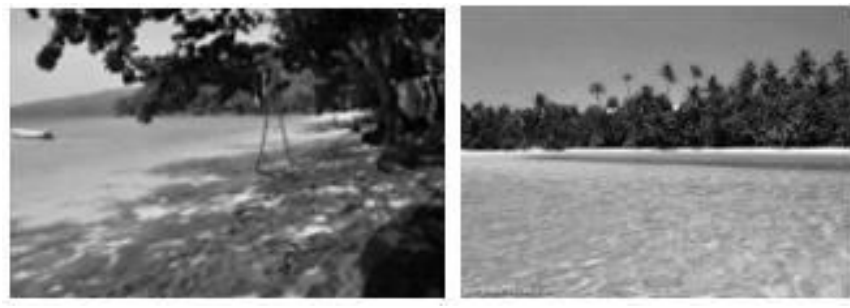

Gambar 3. Kondisi Lingkungan Pantai Gapang

Sumber: Pulauwehaceh.com

Rancangan ini akan menitik beratkan pada upaya pendekatan ekologis, tidak lain ialah untuk menjaga ekosistem alam, yang menjadi daya tarik utama pada industri pariwisata, dan juga untuk mensinergikan objek bangunan yang posisinya langsung berhubungan dengan tepi laut.

Usulan Objek Desain

Untuk menjawab isu diatas, lahirlah gagasan untuk Merancang sebuah Resor ekologis di pulau Sabang yang dilengkapi dengan berbagai fasilitas pariwisata yang menonjolkan kekayaan alam dan juga budaya, guna meningkatkan kualitas ekonomi masyarakat.

Dalam gagasan rancangan ini terdapat beberapa poin utama yaitu:

1) Resor (Penginapan)

2) Wisata bahari (Sarana rekreasi)

3) Dermaga yacht (Event Marine Internasional) 


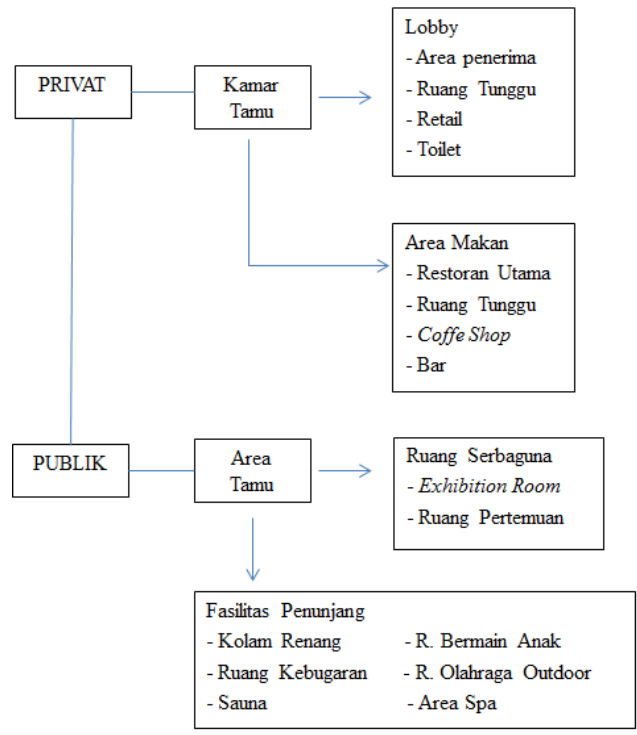

Gambar 4. Pengelompokan dan kebutuhan ruang privat dan ruang public.

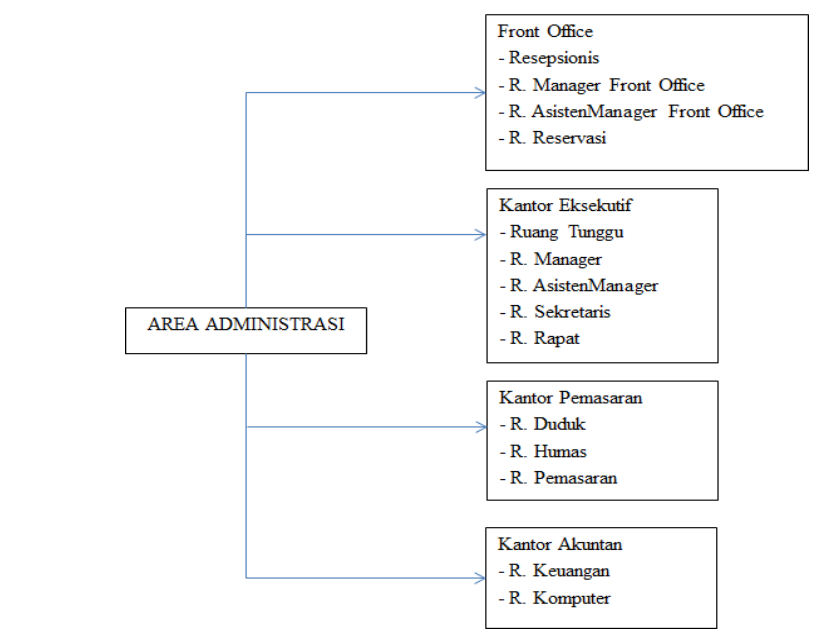

Gambar 5. Pengelompokan dan kebutuhan ruang pengelola.

\section{METODA PERANCANGAN}

Metode yang digunakan dalam desain adalah metode biomimicry. Istilah biomimicry muncul pada awal tahun 1982 dan dipopulerkan oleh ilmuwan dan penulis Janine Benyus. Biomimikri merupakan pemahaman tentang usaha untuk meniru alam baik secara fisik ataupun perilaku. Dalam lingkup arsitektural konsep Mimesis yang sudah lebih dulu berkembang memiliki kesamaan yaitu meniru bentuk, akan tetapi dalam peniruan bentuk Biomimikri hanya meniru bentukan organisme hidup. Berbeda dengan Mimesis yang dapat meniru semua bentukan organik maupun non organik.

Arsitektur biomimikri menggunakan alam sebagai model, acuan dan pedoman untuk memecahkan masalah dalam arsitektur. Arsitektur Biomimikri melihat alam sebagai contoh model dan inspirasi dalam meniru desain alam dan di proses juga diterapkan menjadi konsep buatan manusia. Menggunakan alam sebagai acuan, berarti biomimikri juga menggunakan standar lingkungan alam dalam menilai efisiensi dalam berinovasi. Menggunakan alam sebagai pedoman dan mentor, berarti bahwa biomimikri tidak mencoba untuk mengeksploitasi alam dengan mengekstraksi

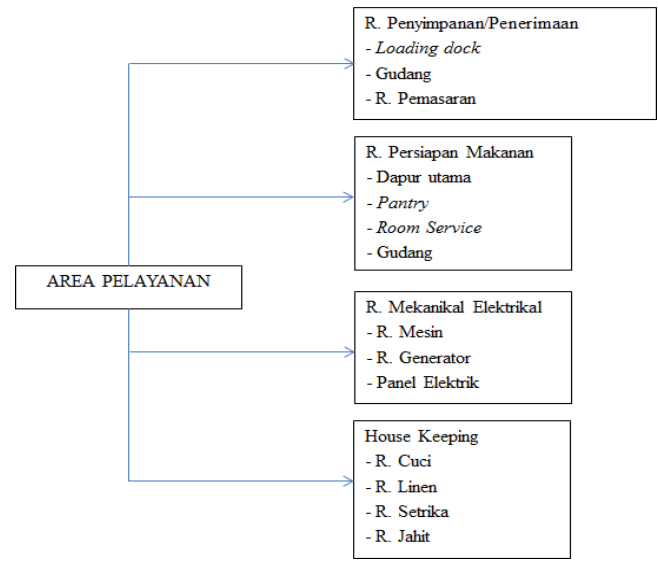

Gambar 6. Pengelompokan dan kebutuhan ruang servis.

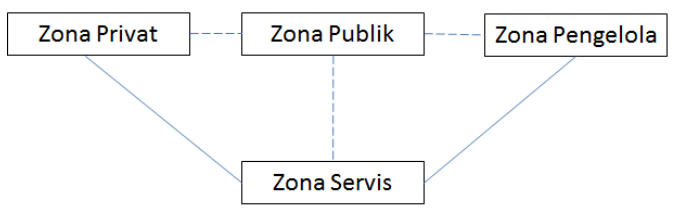

Gambar 7. Konsep ekologis Sun shading.

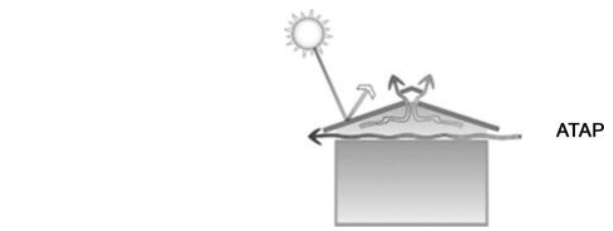

Gambar 8. Konsep ekologis tipe atap.

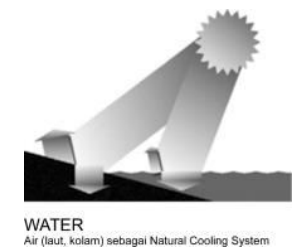

Gambar 9. Konsep ekologis pemanfaatan air pada resor.

barang-barang atau material alam itu, tetapi menghargai alam sebagai sesuatu yang manusia dapat pelajari.

Inovasi arsitektur yang responsif terhadap arsitektur dan alam tak sepenuhnya harus menyerupai objek tanaman atau seekor hewan. Dimana inspirasi arsitektur yang mengambil keistimewaan bentuk intrinsik dari fungsi objek organisme, maka model bangunan yang diproses pada suatu bentuk kehidupan tersebut mungkin juga akan terlihat mirip dengan objek yang ditirunya.

\section{A. Prinsip-prinsip Biomimikri}

1) Bentuk

Konsep Biomimikri pada arsitektur bisa jadi merupakan sebuah penerapan metafora. Karena proses dasar pengambilhan ide yang diambil dari bentuk-bentuk dari alam. Konsep biomimikri dengan penerapan metafora lebih mengarah pada kategori metafora gabungan, karena kesinergian konsepsual dan visual. Tambahannya arsitektur biomimikri dengan proses metafora pada masa kini coba mengaitkan teknologi pada sistem struktur dan material. Selain itu pemodelan bentuk arsitektur dari alam mengacu pada konsep Biomorfik. 


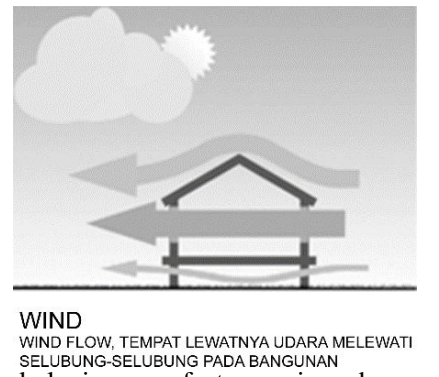

Gambar 10. Konsep ekologis pemanfaatan angin pada resor

Sumber: Bomberek, Zbigniew (2009). Eco-Resorts: Planning and Design for the Tropics.
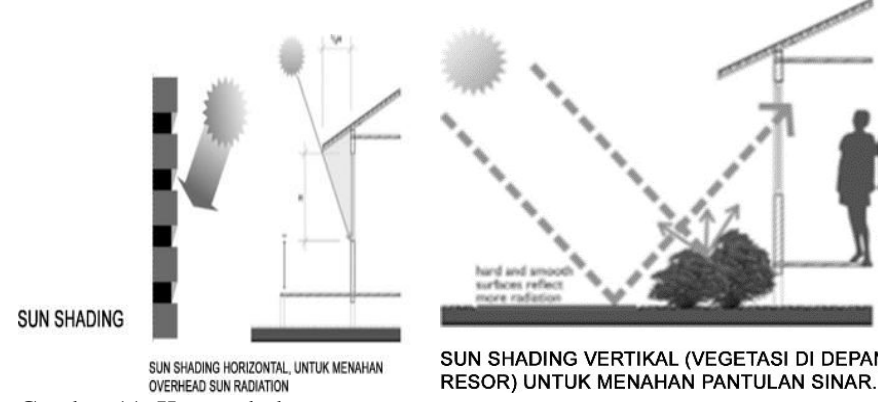

SUN SHADING VERTIKAL (VEGETASI DI DEPAN RESOR) UNTUK MENAHAN PANTULAN SINAR. Gambar 11. Konsep hubungan antar ruang.

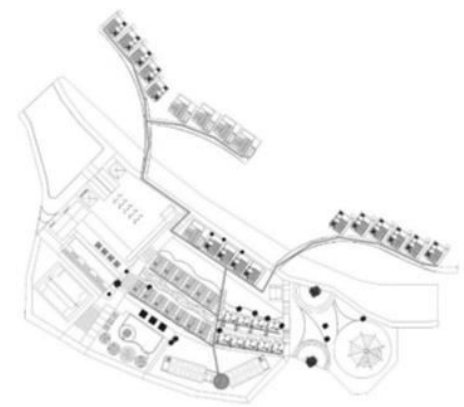

Gambar 12. Konsep penyaluran air bersih.

\section{2) Struktur dan Material}

Konsep mimikri yang diambil pada objek organisme mengarah pada hal fungsional bangunan salah satunya struktur dan material. Maksud Biomimikri yang coba berinovasi dalam menciptakan satu hal yang muktahir atau suatu yang baru, begitu juga penerapannya pada arsitektur yang condong ke permasalahan struktur dan material. Kebanyakan dari studi kasus bangunan Biomimikri menggunakan konsep struktur yang baru atau sekedar modifikasi dari konsep sistem struktur yang sudah pernah ada, tentu konsep struktur yang diambil berdasarkan pemikiran metaforis alam atau lebih dasar mengarah pada biomorfik. Sedangkan pada material menyesuaikan dengan strukturnya, tapi beberapa konsep material Arsitektur Biomimikri lebih dikaitkan pada teknologi digital dan ilmiah.

Prinsip Sustainability

Konsep Biomimikri menjadikan alam sebagai sumber inpirasi, berarti arsitektur juga harus mengacu dengan pendekatan ekologi [3].

Aplikasi prinsip keberlanjutan pada arsitektur yaitu [4]:

- Menggunakan jumlah material secara minimal,

- Memaksimalkan kekuatan struktur,

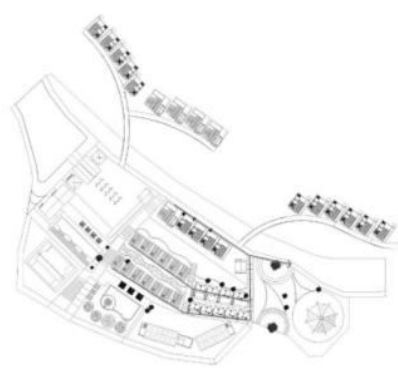

Gambar 13. Konsep penyaluran air kotor.

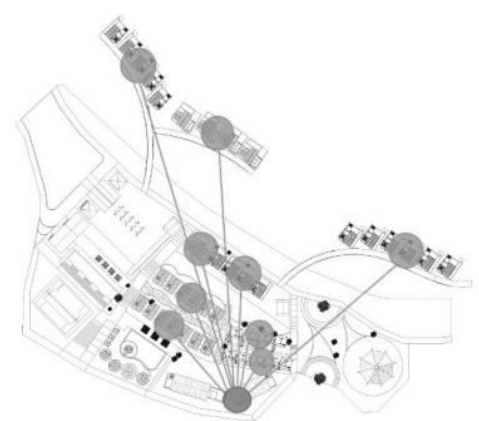

Gambar 14. Konsep pendistribusian sampah
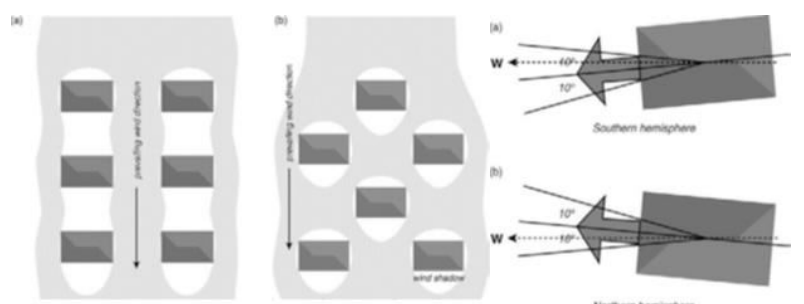

Gambar 15. Konsep positioning bangunan

Sumber: Bomberek, Zbigniew (2009). Eco-Resorts: Planning and Design for the Tropics.

- Menghubungkan warna dan tekstur langsung kepada alam,

- Kontinuitas antara interior dan eksterior

- Memilih material yang efisien dalam memperlihatkan keempat prinsip sebelumnya.

\section{HASIL DAN EKSPLORASI}

\section{A. Eksplorasi Formal}

Salah satu isu utama dalam merancang resort yaitu zoning. Pembagian zona dikonsepkan berdasarkan fungsi ruang (Gambar 4 - 6). Area-area yang "naturally noisy" seperti restoran, playground, entertainment area, dll, harus dipisah dari kamar-kamar tamu. Sehingga menciptakan konsep hubungan antar ruang (Gambar 11).

Penetapan zoning juga disesuaikan dengan kondisi kontur yang sudah ada, tanpa melakukan cut and fill sehingga kembali pada prinsip utama desain yaitu melakukan pendekatan ekologis sehingga tidak menambah kerusakan lingkungan. 


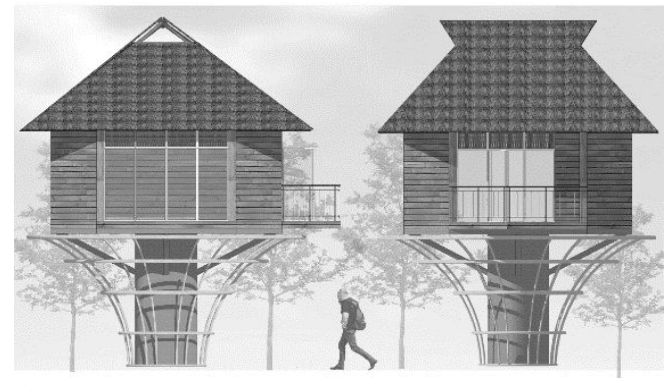

Gambar 16. Desain tipe standard room

\section{B. Positioning}

Untuk menyediakan free movement of air pada site, maka lokasi masing-masing resor harus diberi jarak yang cukup satu sama lainnya. Solusi terbaik dalam penyusunan layout bangunan resort pada area tropis yaitu parallel mengikuti garis pantai. Axis yang panjang harus dijejerkan sejajar barat-timur (Gambar 15).

\section{Ecological Design}

Sesuai dengan metoda dan juga pendekatan desain yang diambil, maka desain resor yang dihasilkan mengikuti prinsipprinsip alam dan sebisa mungkin tidak merusak lingkungan. Desain utilitas dibuat mengikuti kontur lahan sehingga pipapipa air (Gambar 12\&13) dapat memanfaatkan gaya gravitasi dari kontur lahan untuk mengalirkan airnya, tidak sepenuhnya menggunakan pompa air. Distribusi sampah (Gambar 14) juga menjadi salah satu poin yang penting sehingga resor dapat menghasilkan energi dari pengolahan sampah dengan tabung biogas yang telah disediakan.

Desain Room-room pada resor dibuat memiliki 4 tipe (Gambar 16 - 19), sehingga memberikan pilihan kepada pengunjung untuk memilih sendiri desain macam apa yang ingin ia gunakan (everyone is a designer). Hal ini juga menciptakan estetika tersendiri dari berbagai variasi bentuk bangunan yang berpadu pada lahan di pinggir pantai tersebut.

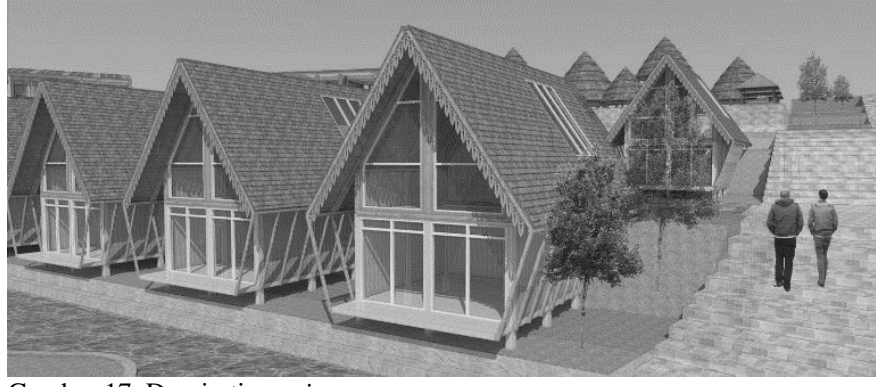

Gambar 17. Desain tipe suite room

\section{KESIMPULAN}

Resor ini merupakan sebuah Objek Arsitektural yang merespon isu tentang keadaan pariwisata di Pulau Sabang, lebih khususnya di Pantai Gapang. Dengan pendekatan Ekologis yaitu dengan menjadikan bangunan ikut berperan aktif baik kepada lingkungan maupun penggunanya, Resor ini diharapkan dapat memberikan persepsi positif bagi penggunanya serta mampu mengatasi beberapa permasalahan yang terjadi.

Sebagai resor yang juga berperan sebagai dermaga kedatangan wisatawan, desain ini diharapkan mampu mencerminkan karakter lokal masyarakat melalui pencerminannya.

\section{DAFTAR PUSTAKA}

[1] K. Hadinoto, Perencanaan Pengembangan Destinasi Pariwisata. Jakarta: UI Press, 1996.

[2] Lindberg and Hawkins, Ecotourism: A Guide for Planners and Managers. 1993.

[3] P. Steadman, The Evolution of Design Biological Analogy in Architecture and Applied Arts. 2008.

[4] E. Tsui, Evolutionary Architecture: Nature As A Basis For Design. 1999. 